\title{
Echocardiographic study of right and left ventricular dimension and left ventricular function in patients with tetralogy of Fallot before and after surgery ${ }^{1,2}$
}

\author{
I. OBERHÄNSLI AND B. FRIEDLI
}

From the Department of Pediatrics and Genetics, University of Geneva, Medical School, Geneva, Switzerland

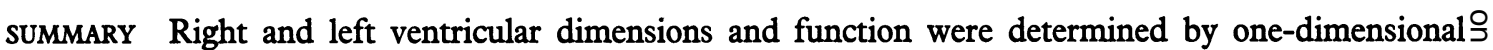
echocardiography in patients with tetralogy of Fallot before and after corrective surgery. Thirty-five $\vec{c}$ children (mean age: 5.9 years) were examined; 5 of them died immediately after operation; 5 had palliative operations only. The remaining 25 had repeat echocardiography 2 to 4 and/or 8 weeks after total correction.

Compared with normal values, preoperative left ventricular dimensions were smaller than expected $\vec{\oplus}$ for body surface area (mean $=85.4 \% \pm 1.9$ SEM, range 65 to $105 \%$ of normal); 21 values were below ${ }^{\circ}$ the 5th centile. Postoperatively, left ventricular dimensions increased significantly and reached normal values in most cases (mean $=103.2 \pm 2.0 \%$ SEM, range 81 to $121 \%$ ). The main increase took place $\sum_{S}$ in the first 4 weeks $(\mathrm{P}<0.001 ;$ mean difference $0.7 \pm 0.14 \mathrm{~cm})$. The 5 children who died after operation had smaller left ventricular dimensions than the survivors $(P<0.01)$.

Left ventricular function was evaluated by measuring mean circumferential fibre shortening, per cent $\stackrel{\mathbb{\Omega}}{\rightarrow}$ shortening, and ejection fraction; they were normal in most patients and diminished only insignificantly윽

after corrective surgery.
Right ventricular dimensions were increased preoperatively but decreased significantly $(P<0.001)$ 范 postoperatively.

Septal movement was normal in direction and excessive in displacement in most patients before operation; immediately after operation it became flat or showed paradoxical motion. Two months $\stackrel{+}{\circ}$ after operation 50 per cent of the children showed a return to normal septal movement. Early appearance 3 . of normal septal movement could be related to the presence of significant pulmonary stenosis.

It is concluded that a high percentage of patients with tetralogy of Fallot have underdeveloped but normally functioning left ventricles which adapt well to the new postoperative state.

In previous investigations, left ventricular volume and mass were found to be diminished in patients suffering from tetralogy of Fallot, after the age of 2 years (Lev et al., 1964; Lev and Eckner, 1964). Furthermore, angiographic evaluations of right and left ventricular function before and after corrective

\footnotetext{
${ }^{1}$ This work was supported by the Swiss National Science Foundation, the Emil Barell Fund, and the Société Académique de Genève.

${ }^{2}$ Preliminary results of this work were presented at the 15th Annual General Meeting of the Association of European Pediatric Cardiologists in Ghent, Belgium, 4-6 May 1977.

Received for publication 4 January 1978
}

surgery showed impaired function of varying degree $\stackrel{N}{\sigma}$ (Levin et al., 1966; Jarmakani et al., 1972; Graham N et al., 1971, 1976). This ventricular function even $\mathcal{C N}^{-}$ remained depressed when palliative shunt proce- 0 dures preceded corrective surgery, though left ventricular and left atrial volumes and mass

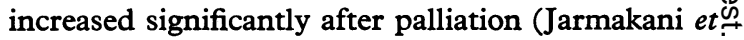
al., 1972; Graham et al., 1976).

The aim of the present study is to investigate right ventricular and left ventricular dimensions and $\stackrel{\odot}{\mathbb{}}$ function using an echocardiographic technique. As $\stackrel{\overrightarrow{\mathbb{Q}}}{\mathscr{Q}}$ left ventricular function and left ventricular volume $\frac{\sigma}{\sigma}$ seemed to be of greatest importance for the outcome of corrective surgery (Kirklin and Karp, 1970), weo 
were particularly interested in studying left ventricular dimensions, left ventricular volume, and left ventricular function before and soon after corrective surgery, and in following the development of septal motion after surgical correction on cardiopulmonary bypass.

\section{Subjects and methods}

Thirty-five patients, 5 days to 14 years old with a mean age of 5.9 years, with tetralogy of Fallot, were examined by single beam echocardiography and cardiac catheterisation. Echocardiographic studies were performed shortly before corrective surgery and then serially 2 weeks and/or 4 weeks and/or 8 weeks after operation whenever possible. Cardiac catheterisation was performed within 24 hours of echocardiographic examination in order to confirm the diagnosis before cardiac surgery, and was repeated 2 months after surgery.

The operative technique was essentially the same for 30 patients undergoing total correction ( 5 of the 35 children underwent only palliative surgery and have not yet had a further operation). A standard procedure was used for surgical correction under hypothermia (down to $18^{\circ} \mathrm{C}$ ) and aortic crossclamping. A patch enlarging the right ventricular outflow tract was used in 20 patients.

Of the 30 patients who underwent a repair procedure, 5 died early after operation (in addition, a baby 5 days old died after palliative operation). Of the remaining 25 patients, 4 underwent a second procedure for severe residual pulmonary obstruction or for an important left-to-right shunt in the case of residual ventricular septal defect.

\section{ECHOCARDIOGRAPHIC TECHNIQUE AND \\ VALIDATION}

Initially the echocardiograms were obtained using a Picker Echoview System 103 interfaced with an Electronics for Medicine VR6 recorder; more recently a Picker $80 \mathrm{C}$ ultrasonoscope and a Honeywell fibreoptic strip chart recorder were used. The electrocardiogram was simultaneously obtained for timing ventricular depolarisation; the $Q$ wave or the beginning of the $\mathrm{R}$ wave was chosen for determining the time of onset of electrical systole. A $2 \cdot 25 \mathrm{MHz}$ transducer with an external diameter of $13 \mathrm{~mm}$ or a $3.6 \mathrm{MHz}$ transducer of $6 \mathrm{~mm}$ diameter, both focused at $7 \mathrm{~cm}$, were used to obtain the echocardiograms. The examination was performed in the supine position in the manner previously described by Feigenbaum (1972) and others. The mitral valve was first located, then the left ventricular posterior wall and interventricular septum were visualised simultaneously with both leaflets of the mitral valve.
From this position the ultrasonic beam was directed several times medially and superiorly in order to obtain a proper and diagnostic sweep for a patient with tetralogy of Fallot (Chung et al., 1973; Tajik et al., 1973; Godman et al., 1974; Morris et al., 1975).

The pulmonary artery was searched for but could only be seen in about 50 per cent of the cases.

The echocardiographic indices studied were right and left ventricular end-systolic and end-diastolic dimensions, left ventricular volume, mean velocity of circumferential fibre shortening and shortening fraction as well as ejection fraction.

Left ventricular ejection time and pre-ejection period were measured on the aortic root echo after determination of aortic cusp opening and closure.

Left ventricular end-systolic dimension was determined along a perpendicular line at the point of closest approximation of the left ventricular endo-

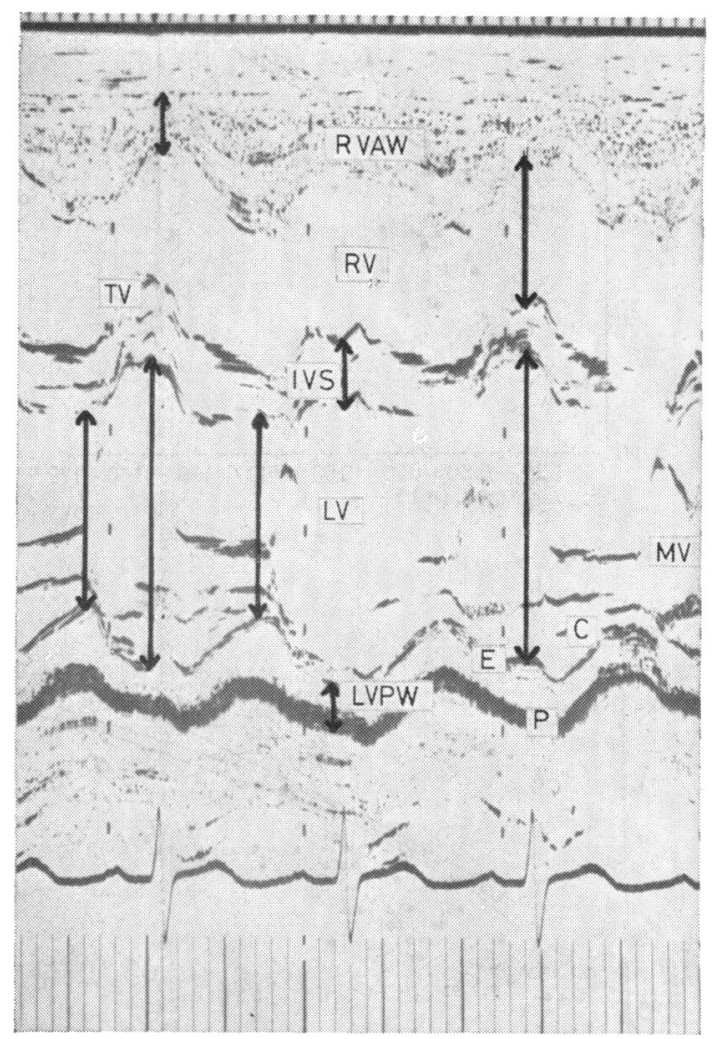

Fig. 1 Echocardiogram of the right and the left ventricles in a 13-month-old child with severe tetralogy of Fallot. The bars indicate the different measurements that have been taken. IVS, interventricular septum; LV, left ventricle; $L V P W$, left ventricular posterior wall; $M V$, mitral valve; $R V$, right ventricle; $R V A W$, right ventricular anterior wall; $E$, endocard; $P$, pericard; $C$, cord. 
cardium and the left septal surface. End-diastolic dimension was measured from the left septal surface to the left ventricular endocardium at the time of onset of ventricular depolarisation as indicated by the $\mathbf{Q}$ or $\mathbf{R}$ wave of the simultaneous electrocardiogram (Fig. 1).

The right ventricular end-diastolic diameter was measured from the right ventricular endocardium to the right septal surface also at the onset of depolarisation. Care was taken to measure the enddiastolic dimension before the posterior movement of the endocardium indicating isovolumic contraction (Meyer et al., 1975).

Left ventricular volumes were calculated accord- ing to the equations of Pombo et al. (1971), Fortuin et al. (1971), Teichholz et al. (1976), and Meyer et $\overrightarrow{\bar{s}}$ al. (1975), and compared with angiographic volume calculations using the area length method from single plane cineangiography (right anterior oblique view) and correcting for magnification and distortion (Green et al., 1967).

Mean velocity of circumferential fibre shortening and percentage fibre shortening were calculated according to Karliner et al. $(1971,1975)$ using the aortic root to determine the ejection time (Paraskos et al., 1971; Karliner et al., 1971, 1975; Kaye et al., 1975). The ejection fraction was calculated using the equation of Meyer et al. (1975).

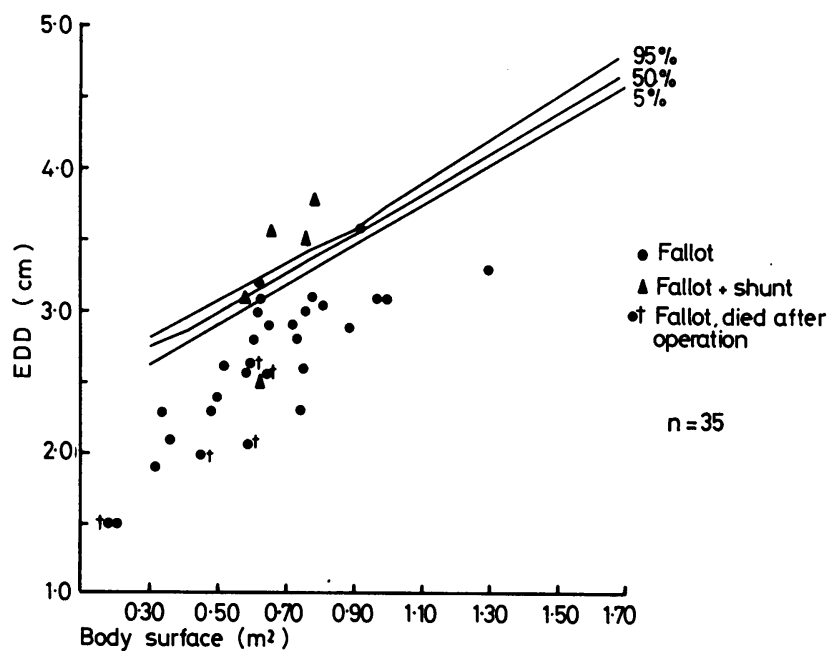

(a)

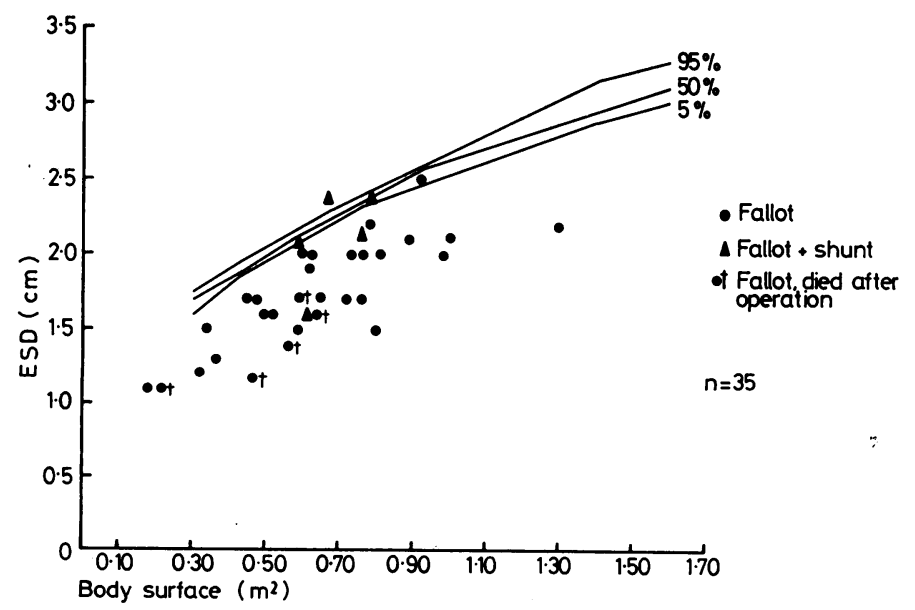

Fig. 2 Preoperative individual enddiastolic (a) and end-systolic (b) left ventricular dimensions in comparison with the normal distribution curve as published by Epstein et al. (1975) for body surface area.

(b) 


\section{STATISTICAL METHODS}

Values are expressed as either individual values or as means \pm standard errors of the mean for the number of observations given. $P$ values of less than 0.05 are considered significant using a paired $t$ test (preoperative samples versus postoperative samples) or using an unpaired $t$ test (differences between groups). A linear regression equation was calculated for angiographic versus echocardiographic enddiastolic volumes (Snedecor and Cochran, 1970).

\section{Results}

\section{(a) LEFT AND RIGHT VENTRICULAR DIMENSIONS}

Left ventricular end-systolic and end-diastolic dimensions in our patients were related to body surface area and compared with the normal values contained in the distribution curves published by
Epstein et al. (1975) (Fig. 2a, b). Before operation, both dimensions were much below normal; the mean value for end-diastolic dimension was $85.4 \pm$ 1.9 per cent with a range between 65 and 105 per cent of normal; the corresponding values for endsystolic dimensions were $80 \pm 2 \cdot 3$ per cent with a range from 52 to 101 per cent. The 5 patients who died at operation were not only small children but also had particularly small left ventricles for their body surface area. The 5 patients who had undergone a previous palliative procedure showed dimensions that approached or exceeded normal values (range 81 to $105 \%$ ). Preoperative data are shown in Table 1.

Postoperatively, left ventricular diameters increased significantly and exceeded normal values in 11 cases (Table 1, Fig. 3a, b). The mean value for end-diastolic dimensions was $103.2 \pm 2.0$ per cent of normal with a range between 81 and 121 per cent;

Table 1

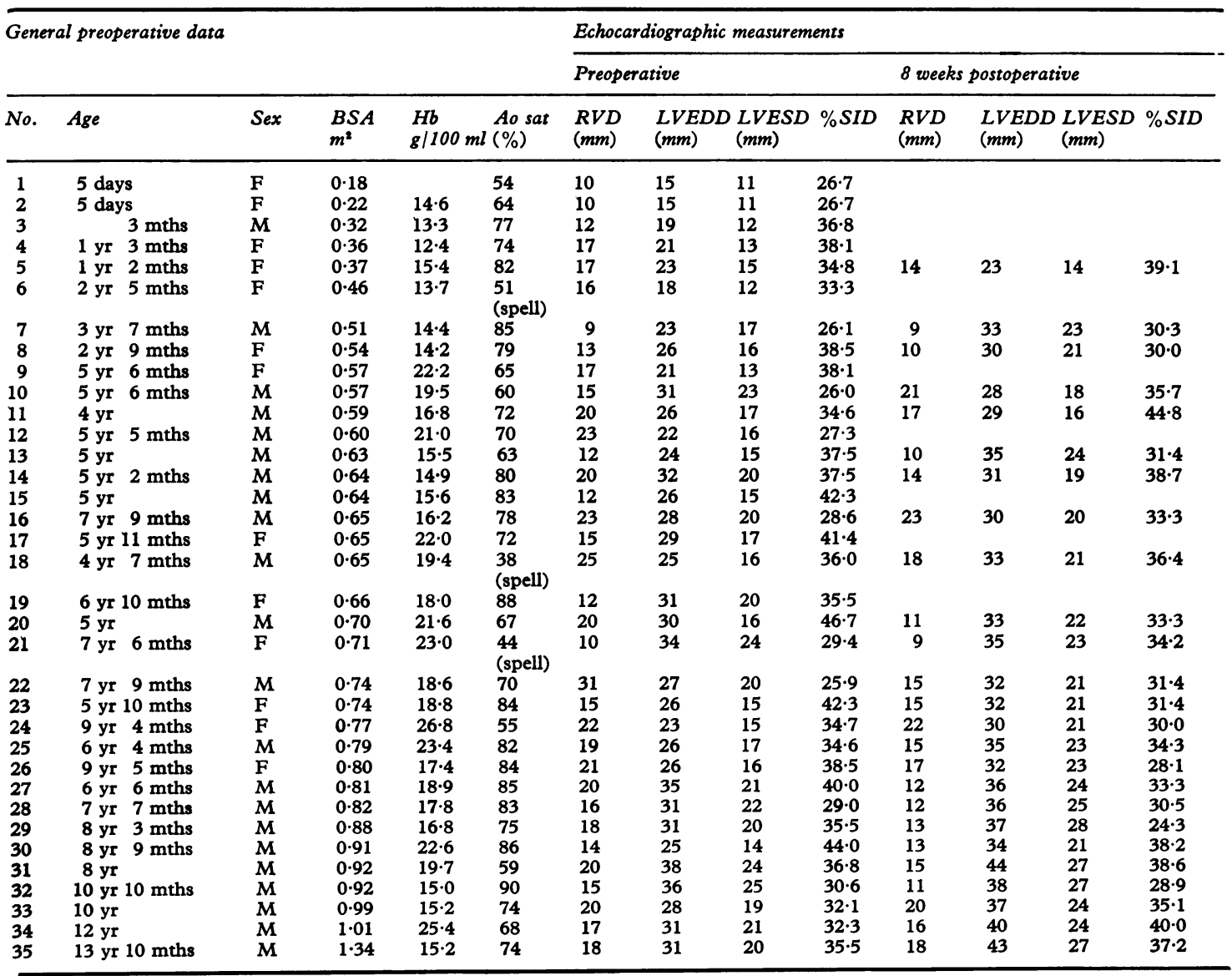

BSA, body surface area; $\mathrm{Hb}$, haemoglobin; Ao sat, aortic saturation; RVD, right ventricular dimension; LVEDD, left ventricular enddiastolic dimension; LVESD, left ventricular end-systolic dimension; \% SID, per cent shortening of the internal dimension. 


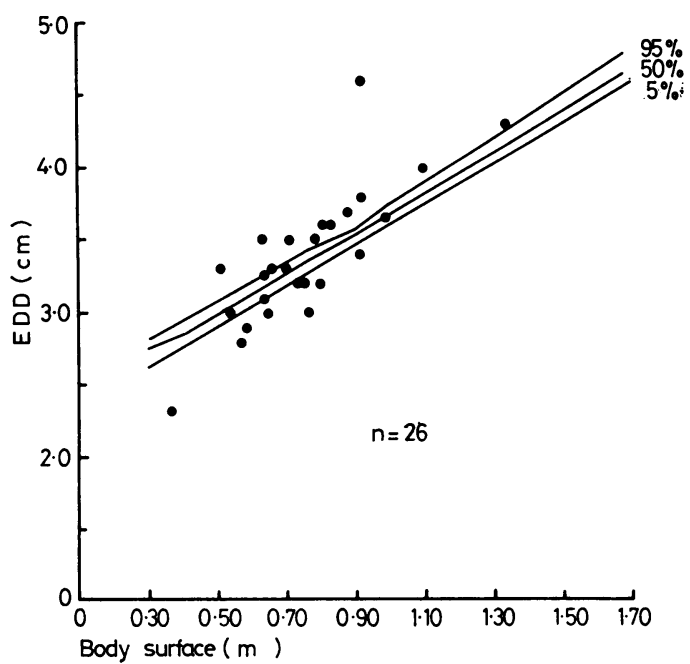

(a)

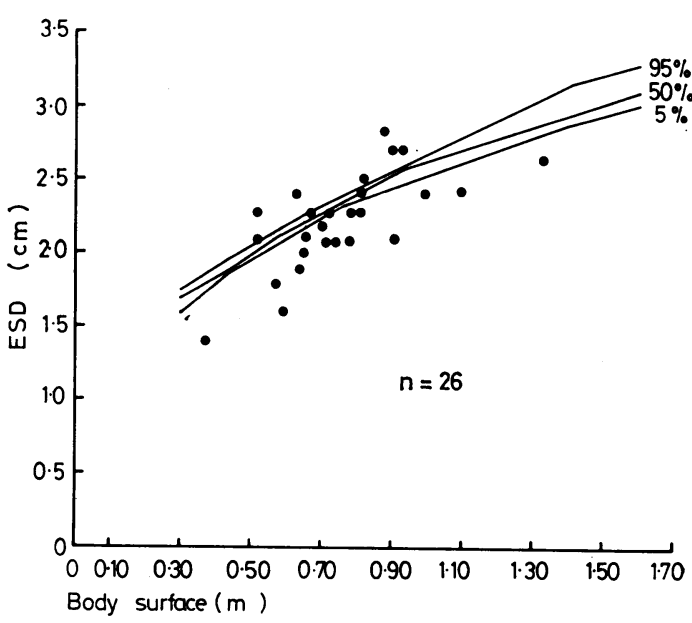

(b)

Fig. 3 Measurements of left ventricular end-diastolic (a) and end-systolic (b) dimensions for 26 patients 2 months after successful operation, in comparison with the normal distribution curve for body surface area as published by Epstein et al. (1975).

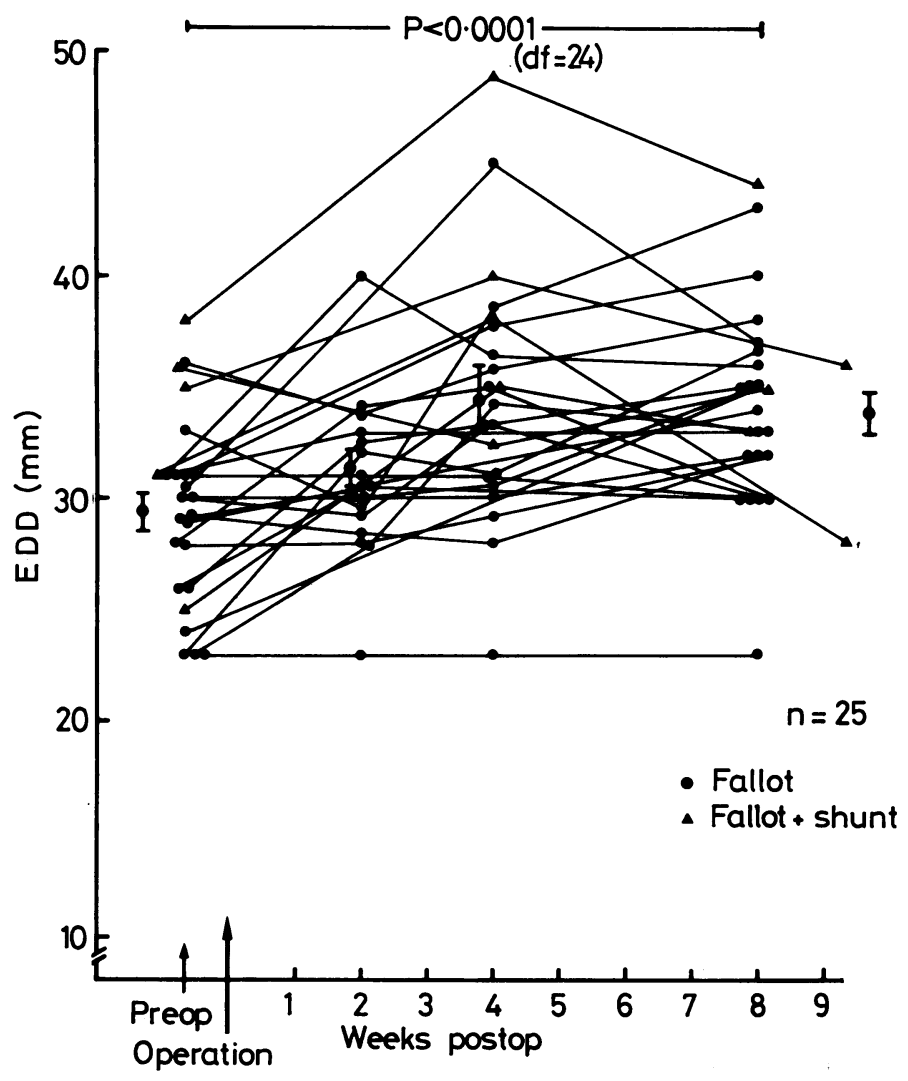

Fig. 4 Individual sequence of left ventricular end-diastolic measurements as a function of time before and after operation. The bars indicate mean values of each group with the standard error of the mean at a given time. 
the corresponding end-systolic value was $97 \cdot 3 \pm$ 2.4 per cent, with a range from 71 to 116 per cent.

In Fig. 4, the pre- and postoperative values for end-diastolic dimensions are combined; the sequence of changes in each individual case is given as a function of time after corrective surgery. The main and most significant increase in the left ventricular diameter takes place within the first 4 weeks (the mean increase is $0.52 \pm 0.15 \mathrm{~cm}, \mathrm{P}<$ 0.001 ). Between the 4th and the 8th week after surgery changes are slight and variable for individual cases; on the whole, end-diastolic dimension diminishes slightly but insignificantly.

Right ventricular end-diastolic dimensions were found to be increased preoperatively (160 $\pm 6.3 \%$ of normal); they diminished significantly in the twomonth period after operation (the mean decrease is $0.28 \pm 0.08 \mathrm{~cm}, P<0.001)$. In 3 patients with a significant residual pulmonary artery gradient (more than $60 \mathrm{mmHg}$ ) the right ventricular dimension did not diminish. Practically no change in dimension was seen in children whose values were normal before operation and in the one case who had severe pulmonary insufficiency (Fig. 5).

\section{(b) COMPARISON WITH ANGIOGRAPHIC VOLUME CALCULATIONS}

The best correlation between echo and angio techniques was found when the equation of Meyer et al. (1975) for calculating the volume from the echocardiogram was used, as shown in Fig. 6. The regression equation reads $\mathrm{y}=0.93 \mathrm{x}+4.8 ; \mathrm{r}=$ $0.92 ; n=41(P<0.001)$.

Before corrective surgery, echocardiographic calculations tended to underestimate left ventricular volume, while postoperatively echocardiography overestimated left ventricular volume in comparison with angiocardiographic measurements.

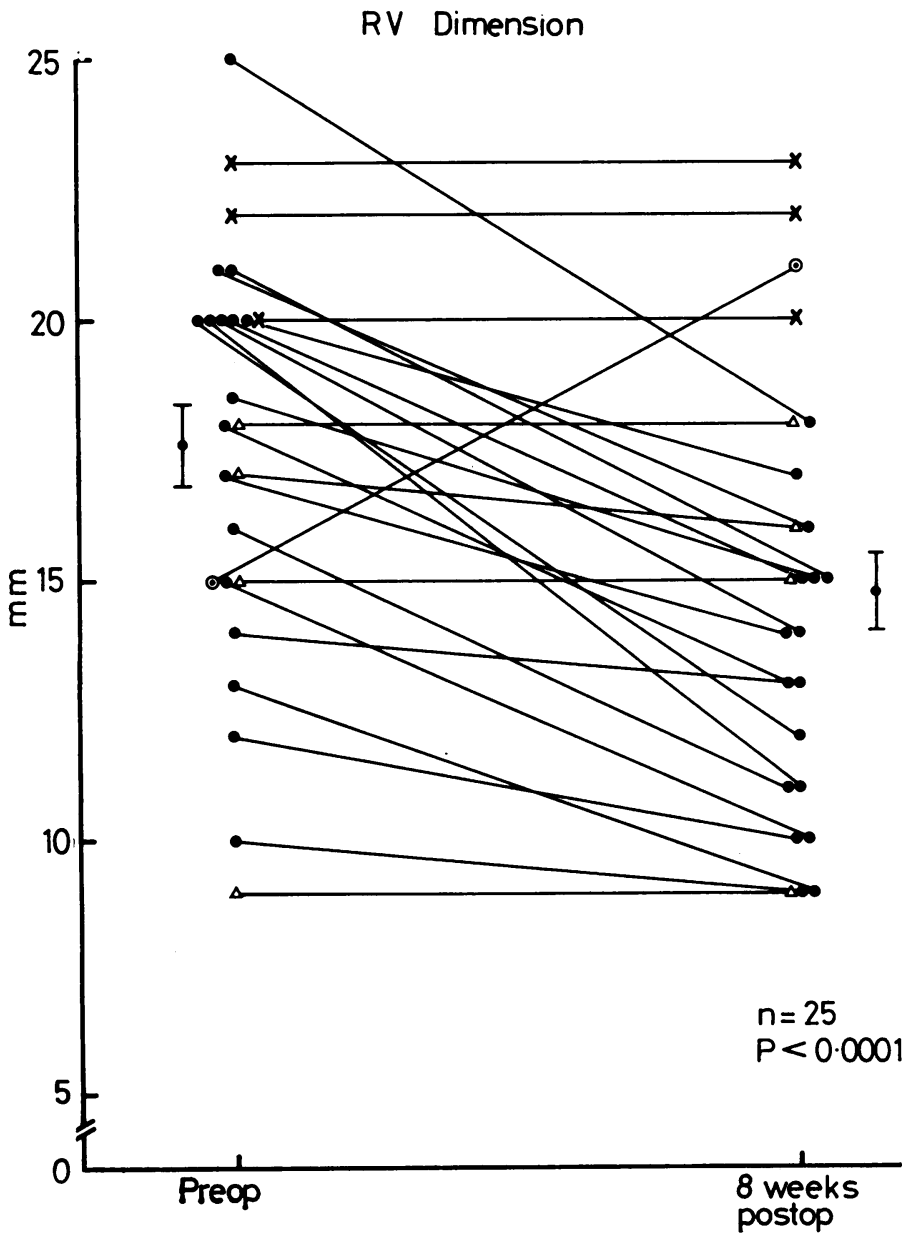

Fig. 5 Right ventricular dimensions before operation and 8 weeks after operation. In most patients, right ventricular dimension decreased significantly (O); exceptions are: patients whose right ventricular dimension was normal before surgery $(\triangle)$, patients with conspicuous residual pulmonary stenosis $(X)$ and one patient with right and left heart failure $(\odot)$, and significant pulmonary insufficiency after operation. 


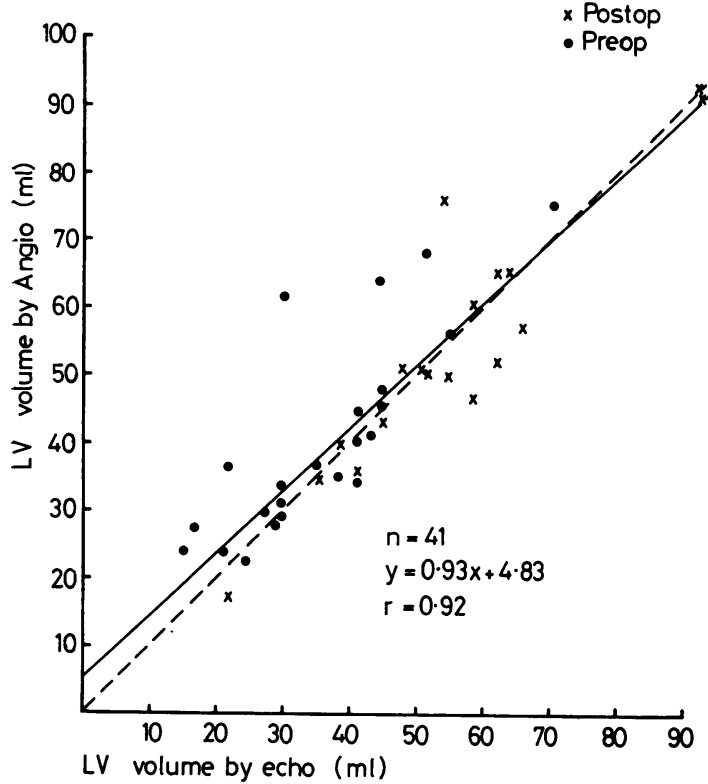

Fig. 6 Comparison between angiographic and echocardiographic left ventricular volume calculations. The dotted line is the line of identity while the solid one is the regression line for the total group of observations (before and after operation).

Calculated left ventricular volumes (expressed as $\mathrm{ml} / \mathrm{m}^{2}$ ) were compared before and after operation in 25 children undergoing correction for tetralogy of Fallot (Fig. 7). The mean value of left ventricular volumes was $55.6 \pm 3.04 \mathrm{ml}$, with a range from 29 to $89 \mathrm{ml}$ before surgical intervention. Thus left ventricular volume was abnormally small in 15 $(60 \%)$ of the 25 patients and normal in only 4 children (16\%).

Eight weeks after the repair procedure the left ventricular volumes had returned to normal or exceeded the normal range (mean $72.8 \pm 2.3 \mathrm{ml} / \mathrm{m}^{2}$ body surface area with a range of 54 to $102 \mathrm{ml}$, $P<0.0001$ ) for all except 3 patients whose volume also increased but not to normal. An abnormally large postoperative volume was found in 3 patients; it could be related to a large left-to-right shunt in 1 case (residual) and to left ventricular failure in 2 , but 3 to 4 months after operation these 2 had also reached normal values.

Ten patients underwent palliative shunts; as a result of this procedure the left ventricular dimension and volume of 8 patients had returned to normal, while in 2 it remained unchanged. For the total group the mean value was 95 per cent of normal (range 60 to $120 \%$ ).

\section{(c) LEFT VENTRICULAR FUNCTION STUDIES}

Ejection fraction (Fig. 8a)

Preoperatively the mean value for 35 patients was $62 \pm 1$ per cent with a range of 52 to 70 per cent. Six children of the total group of 35 had values below the lower limit of normal (which is $58 \%$ ) (Jarmakani et al., 1972). Independently of septal movement postoperatively, the ejection fraction 2 and 4 weeks after operation showed nearly identical results (mean value $64 \pm 2 \%$ and $63 \pm 1 \%$, respectively). Two months after corrective surgery the mean value for a total of 25 patients had slightly but insignificantly decreased $(61 \pm 1 \%$ with a range of 48 to $73 \%$ ).

A diminished ejection fraction was found preoperatively in 6 children; 3 of them still had abnormal values 8 weeks postoperatively. In addition, 4 children who had normal values before were found to have low values after operation. No correlation between low ejection fraction and postoperative mortality was found.

Per cent shortening fraction and mean rate of circumferential shortening (Fig. 8b, c)

Preoperatively, the shortening fraction of the internal diameter was within the normal range in 29 of 35 observations (mean value $33.8 \pm 0.7 \%$ ). Six patients were found to have diminished left ventricular function not only by diminished percentage of shortening fraction (below $30 \%$, the lowest value being $26 \%$ ) but also by ejection fraction as described previously.

Two and 4 weeks after operation the percentage shortening fraction increased significantly (37.5 \pm $1.7 \%$ ). This increase could have been the result of digitalisation which formed part of the postoperative treatment. Nevertheless, 3 of 17 and 3 of 21 patients, respectively, showed a reduced contractility, with values below or at 30 per cent. Eight weeks after operation 22 of 25 successfully operated children had normal values (mean value $34 \cdot 1 \pm$ $0.9 \%$ ) and 3 had borderline shortening of the internal diameter $(30 \%)$; the mean value differed only insignificantly from those obtained preoperatively.

\section{Mean rate of circumferential fibre shortening}

The mean rate of circumferential shortening was also evaluated before and after operation. All the values calculated were found to be above $1.04 \mathrm{circ} / \mathrm{s}$ (the lower limit of normal) in the preoperative group (Cooper et al., 1972; Kaye et al., 1975; Tynan et al., 1975). Those patients who had diminished ejection fractions and diminished or borderline per cent shortening of internal diameter, were found 


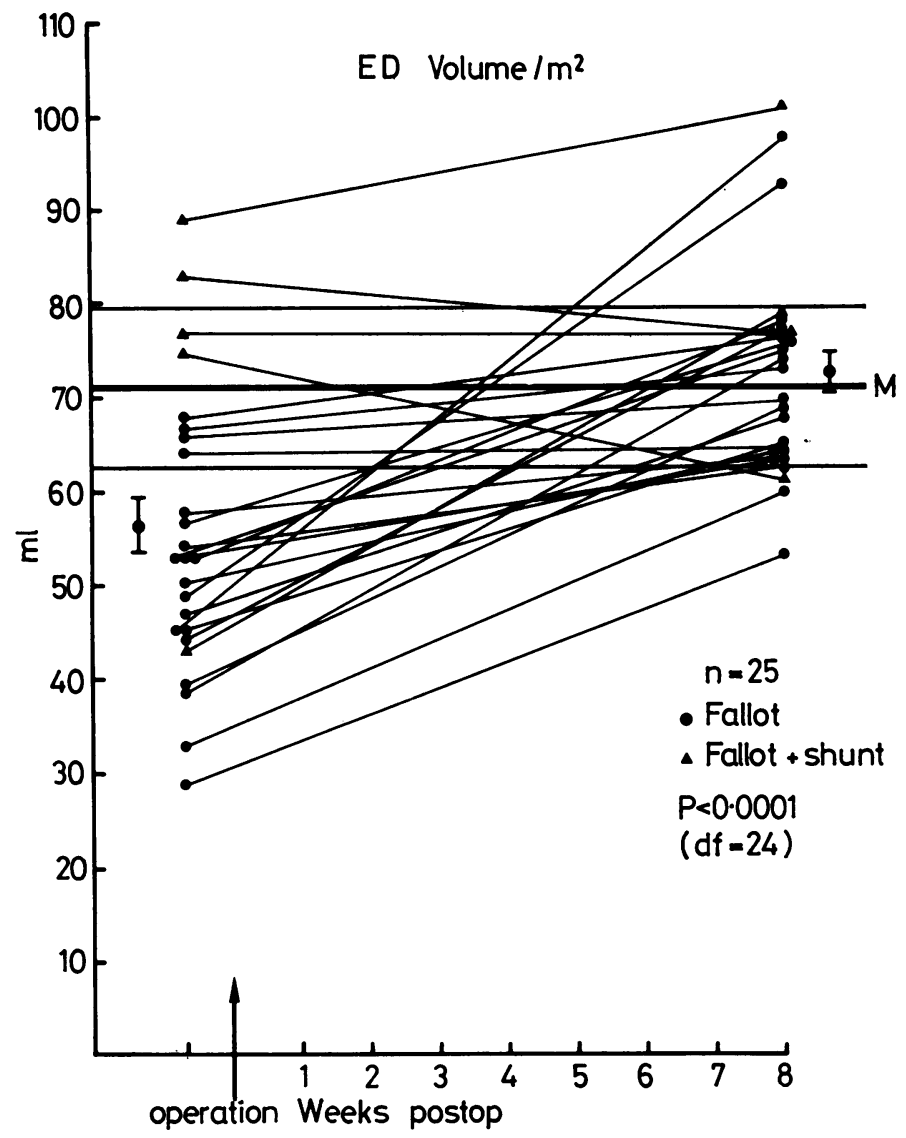

Fig. 7 Comparison of our left ventricular end-diastolic volume indices $\left(/ m^{2}\right)$ determined before and after operation by echocardiography with the normal values, mean, and standard deviations (horizontal lines), as published by Graham's group (1971). The vertical bars indicate pre- and postoperative mean values and the standard error of the mean.

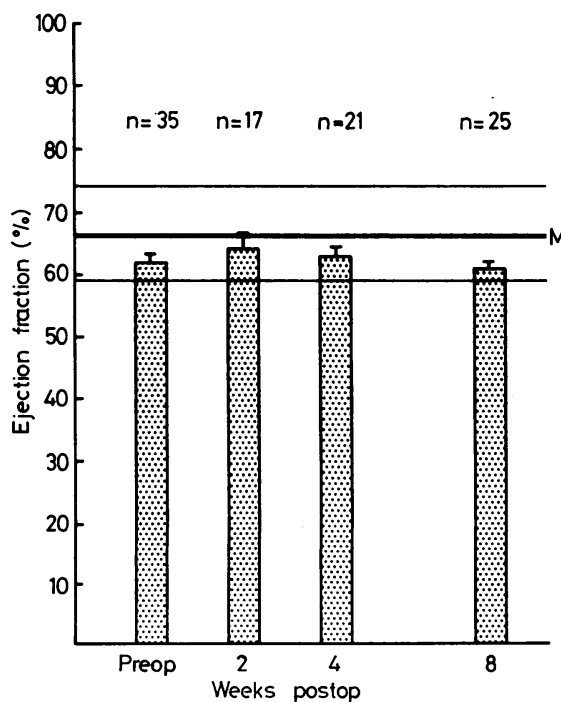

(a)

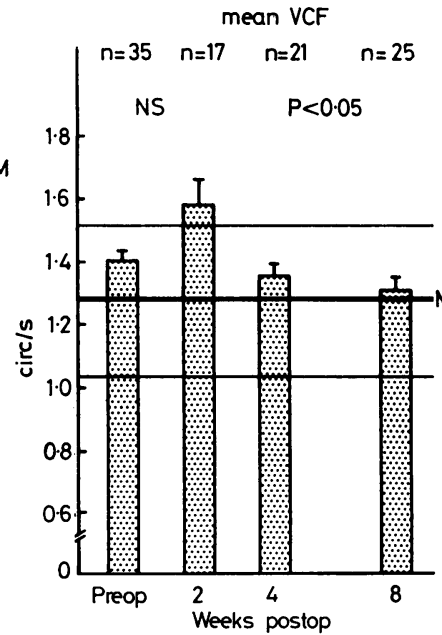

(b)
$\%$ SID

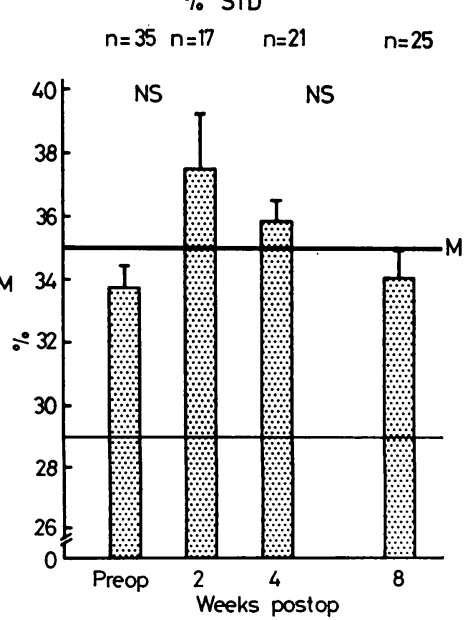

(c)

Fig. 8 Left ventricular function indices as a function of time before and after operation. The horizontal lines indicate normal mean values and the standard deviations. The columns indicate our mean values with the standard error of the mean. Mean VCF, mean velocity circumferential fibre shortening; $\% S I D$, per cent shortening of internal diameter. 


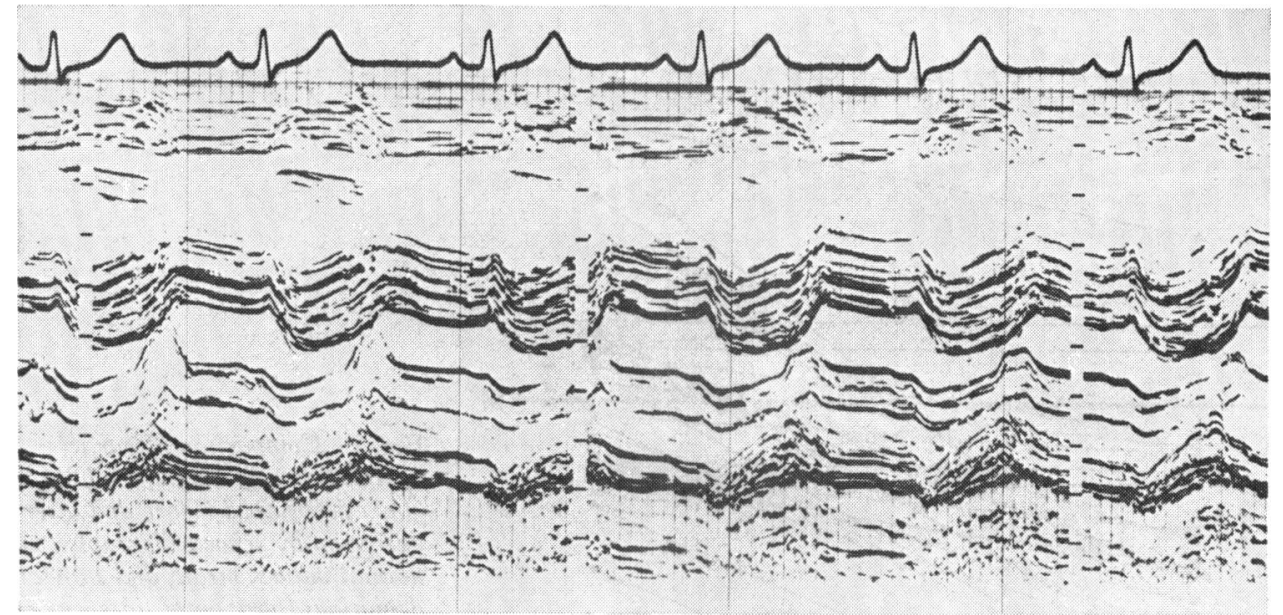

Fig. 9(a)

Fig. 9 Different types of septal movement seen after operation. (a) Normal but excessive septal movement; (b) abnormal flat movement (type B); (c) abnormal movement with double posterior movement during ventricular systole and diastole; (d) abnormal paradoxical movement.

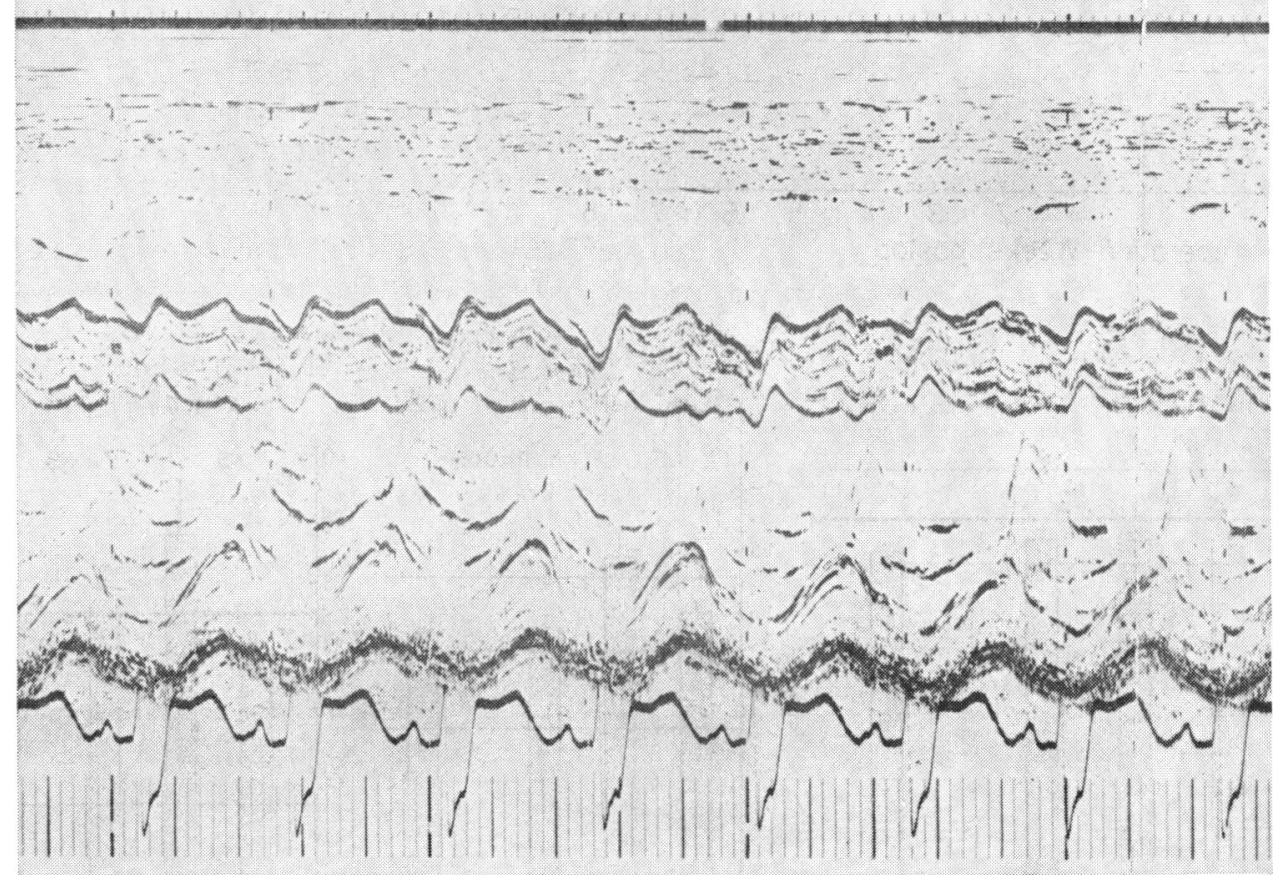

Fig. 9(b)

to have low normal mean circumferential fibre shortening rates $(1.05$ to $1 \cdot 15)$. Immediately after operation mean circumferential fibre shortening rate increased and exceeded the upper limit of normal. $\bar{O}$ Statistically this increase was not significant; when 8 the total groups were compared, it was howevero 


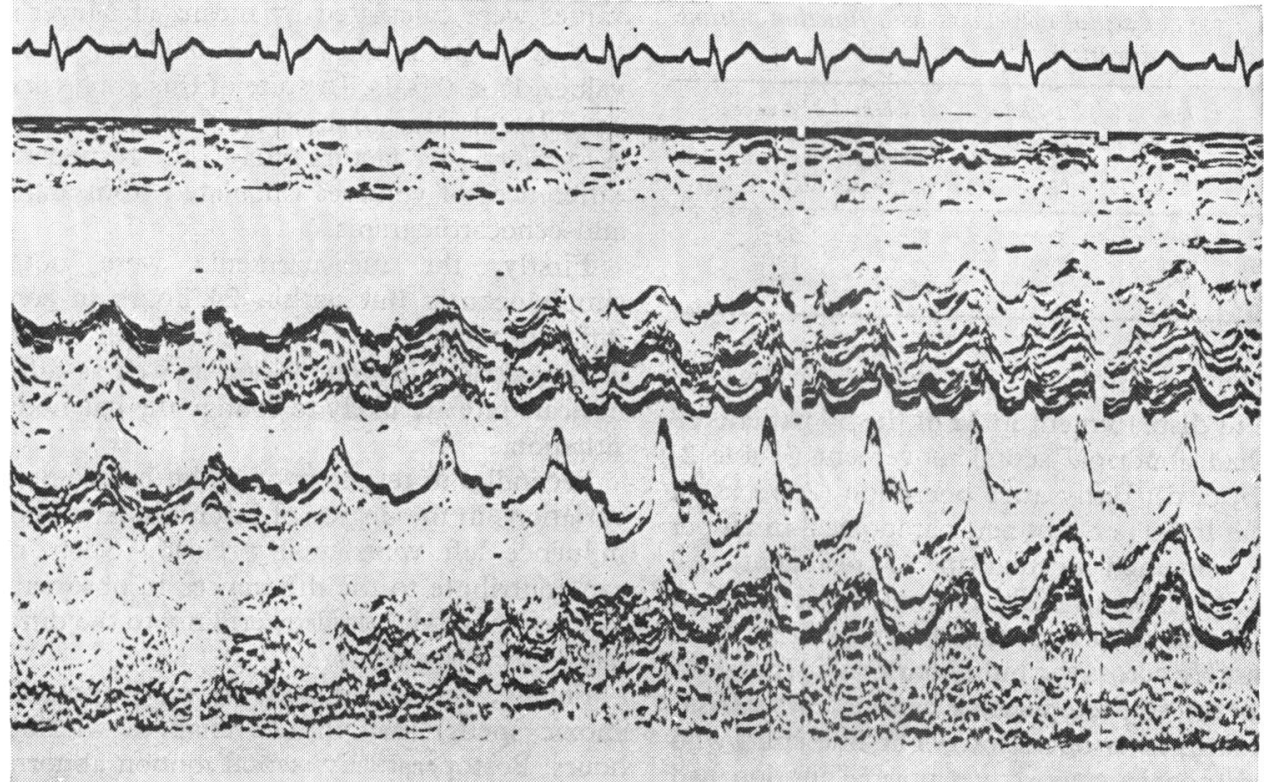

Fig. 9(c)

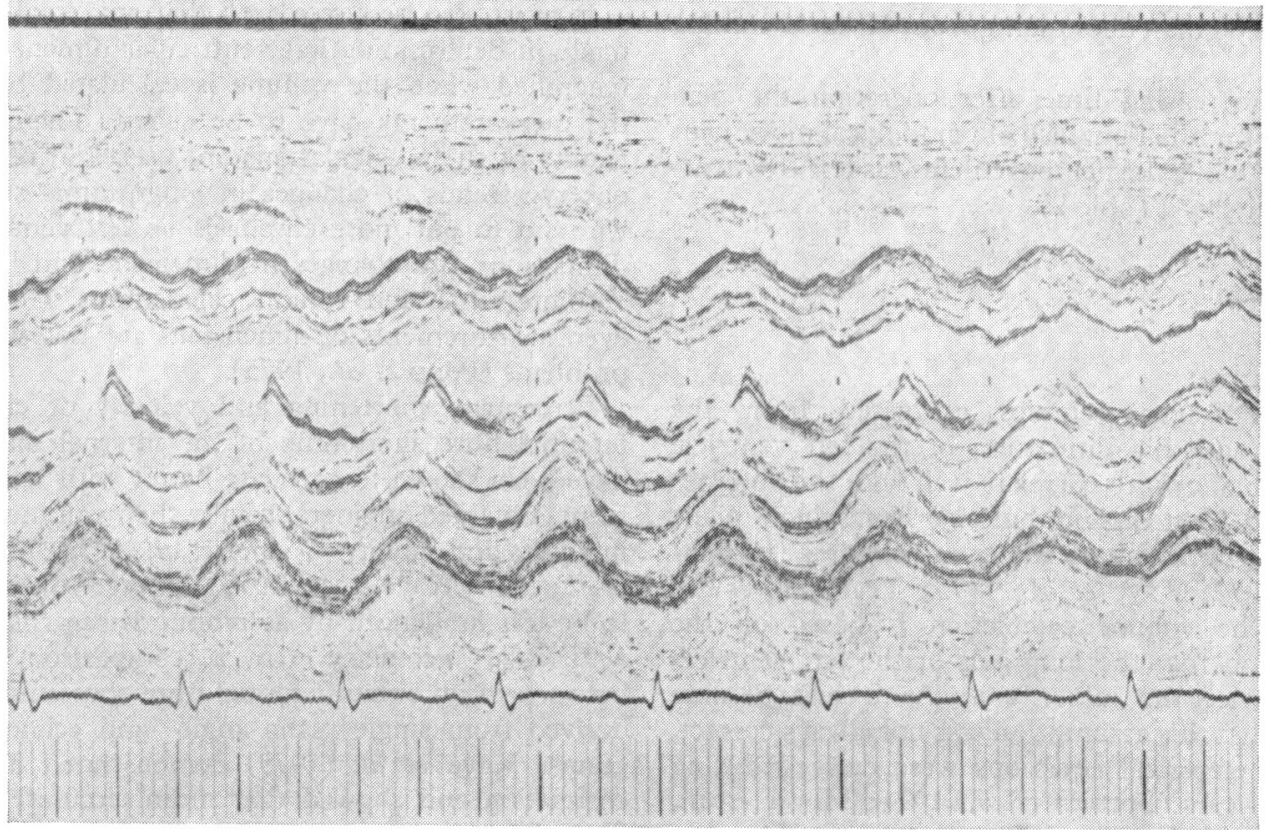

Fig. 9(d)

significant in 17 patients studied longitudinally before and after operation (paired t test, $\mathrm{P}<0.025$ ).

Eight weeks after operation the mean value decreased to $1.32 \pm 0.04 \mathrm{circ} / \mathrm{s}$. One of 25 patients had an abnormally low value of $0.95 \mathrm{circ} / \mathrm{s}$ and 6 
Table 2 Types of septal movement as a function of time (before and after operation)

\begin{tabular}{lllll}
\hline $\begin{array}{l}\text { Septal } \\
\text { movement }\end{array}$ & $\begin{array}{l}\text { Pre- } \\
\text { operatively }\end{array}$ & $\begin{array}{l}2 \text { weeks } \\
\text { post- } \\
\text { operatively } \\
(N=17)\end{array}$ & $\begin{array}{l}4 \text { weeks } \\
\text { post- } \\
\text { operatively } \\
(N=21)\end{array}$ & $\begin{array}{l}8 \text { weeks } \\
\text { post- } \\
\text { operatively } \\
(N=26)\end{array}$ \\
\hline Normal & $95 \%$ & $31 \%$ & $38 \%$ & $50 \%$ \\
Flat (type B) & $6 \%$ & $50 \%$ & $38 \%$ & $19 \%$ \\
Paradoxical & $3 \%$ & $19 \%$ & $24 \%$ & $31 \%$ \\
\hline
\end{tabular}

excessive in displacement in 32 of the 35 patients; 3 children had abnormal septal movement (Table 2; Fig. 9a, b, c, d). Early after operation (2 weeks) it became flat in 50 per cent and paradoxical in 19 per cent but remained normal in 31 per cent. All patients with a persistently normal motion except one were found to have a residual gradient of more than $30 \mathrm{mmHg}$ across the pulmonary valve (range 35 to $65 \mathrm{mmHg}$ ) at postoperative cardiac catheterisation ( 2 months after operation). The one child who had no pulmonary stenosis yet normal motion had an important residual left-to-right shunt at ventricular level. Those patients with a persistent flat or paradoxical movement 2 months after operation had pulmonary gradients ranging from 10 to $35 \mathrm{mmHg}$ only.

With increasing time after operation the percentage of normal but also of paradoxical movement increased while the flat movement was less frequently encountered (Table 2).

\section{Discussion}

\section{(A) METHODS}

Left ventricular volumes estimated from the echocardiographic dimension of the left ventricle have been shown to correlate well with the volumes calculated from biplane but also from single plane cineangiograms in both adults and children (Feigenbaum, 1972; Kaye et al., 1975; Teichholz et al., 1976). The volume calculation is based on the assumption that the long axis of the left ventricle equals twice the minor axis. As it had become evident that this assumption was not always correct, different empirical equations were derived during the past years (Fortuin et al., 1971; Meyer et al., 1975; Teichholz et al., 1976).

In order to find out which of these equations would fit best for tetralogy of Fallot patients, we compared volumes calculated according to the formulae of Feigenbaum, of Fortuin, of Teichholz, and of Meyer with our angiographically determined values before and after corrective surgery. The best correlation was found when our echocardiographic values were calculated by means of Meyer's equation as shown in Fig. $6(r=0.92$ for 41 compared values, $P<0.001$ ). In spite of this good correlation considerable deviations were found in some cases. A variety of factors may be responsible for differences of volumes calculated from angiograms and echocardiograms.

Firstly, the measurements were not made simultaneously but within 24 hours in somewhat different conditions. Thus sedation of the patients during cardiac catheterisation as well as differences in heart rate are likely to change the haemodynamic situation.

Secondly, in tetralogy of Fallot before operation, variations in the degree of infundibular stenosis can influence left ventricular preload. Such changes can contribute to the differences in observations in any one method, but also certainly to the differences between two methods.

Finally, the administration of propranolol (for anoxic spells) may induce changes within a few hours. Postoperatively, septal motion abnormalities could be the reason for some important differences in angiographic and echocardiographic volume calculations.

It must also be considered that any small error made in determining left ventricular dimensions is magnified when the volume is calculated because the measurements have to be cubed. Though the results of these calculations are useful in order to observe trends of changes in longitudinal studies, we tend to put more emphasis on left ventricular dimensions and changes in dimension and less on absolute values and volume calculations. However, even measurements of dimensions are not without problems (Popp et al., 1975).

Percentage shortening and velocity of circumferential fibre shortening of the internal diameter have been shown to correlate better with measurements obtained angiographically than volumes both in adults and infants (Cooper et al., 1972; Karliner et al., 1975; Kaye et al., 1975). These indices seem to be less influenced by assumptions regarding left ventricular geometry. In a comparison study between mean circumferential fibre shortening rate derived from single plane angio- and echocardiograms, Kaye et al. (1975) demonstrated a good correlation and showed that mean circumferential fibre shortening rate was the more sensitive index. It is known, however, that these indices are also influenced by a number of variables including fibre length at rest (preload), ventricular systolic pressure (afterload), chamber shape, and heart rate. Increased afterload diminishes mean circumferential fibre shortening rate, while certain drugs (digoxin) increase it (Karliner et al., 1975). Care must, 
therefore, be taken in the interpretation of results, whether obtained by angiographic or echocardiographic techniques.

\section{(B) RESULTS}

A decreased left ventricular end-diastolic volume has been reported in patients with tetralogy of Fallot both in cineangiographic studies and anatomical specimens (Lev et al., 1964; Jarmakani et al., 1972). This 'hypoplasia' of the left ventricle was specially evident when the patients' age exceeded 2 years. Our data confirm this underdevelopment of left ventricular size (as shown in Fig. 2a, b and Fig. 7). Contrary to the study by Jarmakani, no clear correlation was found between preoperative left ventricular end-diastolic dimension and haemoglobin or haematocrit.

From our data it appears that the young children with severe left ventricular hypoplasia have a higher operative mortality though several were successfully operated on with left ventricular diameters of only 65 per cent of normal. This seems to favour a palliative procedure before total correction in patients with small left ventricles. In our study 5 patients with small left ventricular dimensions did have shunt procedures followed by total correction. Though none of them died, 3 of them had stormy postoperative courses with prolonged left ventricular failure. We are, therefore, not convinced that small left ventricular volumes are an indication for palliation rather than corrective surgery (Graham et al., 1976). The causes of the left ventricular underdevelopment in tetralogy of Fallot patients are not well known.

One could speculate that the stenosed pulmonary outflow tract together with the malaligned aorta favours flow from the right ventricle to the ascending aorta during fetal development, upsetting the balance between right and left ventricular output. This is in fact unlikely to cause left ventricular underdevelopment because most of the left ventricular filling in the fetus occurs from the inferior vena cava through the foramen ovale and not through the pulmonary veins. After birth, when left ventricular output depends essentially on pulmonary blood flow, the decreased pulmonary blood flow occurring in tetralogy of Fallot patients diminishes pulmonary venous return as well as left atrial and left ventricular filling. One would thus expect a progressive increase in relative left ventricular hypoplasia with increasing age of the patients. So far we have not been able to show this in our study. Indeed the regression line for left ventricular dimension versus body surface area in patients with tetralogy is not significantly different from the normal regression line. After corrective surgery the left ventricular dimension increases. This increase is relatively slow and insignificant up to 2 weeks after operation but 4 weeks after the operation it becomes highly significant $(P<0.001)$. Between 4 and 8 weeks after operation there are only small changes, the general tendency being a levelling off.

The right ventricular dimension which was large preoperatively in most of our patients decreased and approached normal values whether or not an outflow patch was used at surgery. Right ventricular dimension did not decrease in the presence of a moderate or severe outflow tract obstruction or in haemodynamically significant pulmonary incompetence. As we did not investigate right ventricular function indices, a comparison with the results obtained by Graham's group (1976) cannot be made.

The different indices used for left ventricular function followed a similar pattern of change before and after operation. Abnormal function is suggested in only a small percentage of patients $(17 \%)$ by abnormalities of 2 if not all 3 indices. Such inadequate left ventricular function has been recognised previously in angiographic studies by Graham's group $(1971,1976)$. Its cause is as yet unknown, but abnormal myocardial metabolism from hypoxia with myocardial fibrosis as a consequence could be responsible (Friedli et al., 1977).

By 2 weeks after corrective surgery all 3 indices of left ventricular function increased temporarily; this increase was insignificant except for per cent SID. It could be explained either by an increase in preload, a change in heart rate, or the effect of treatment with digoxin and diuretics (Karliner et al., 1975). Further investigations in the earliest postoperative phase will be necessary to understand this effect. Four and 8 weeks after operation all values decreased but remained on the mean in the normal range.

Because abnormal septal movement could bias calculations of left ventricular function indices, a comparison of pre- and postoperative values was made for patients with normal septal motion only. The same trends are observed as for the total group (Fig. 10). The fact that mean circumferential fibre shortening rate is within normal limits even in cases with abnormal ejection fraction and per cent SID makes us wonder whether the lower limits of normal should be put at a value of $1 \cdot 15$ or even $1 \cdot 2$.

It must be emphasised that with single beam echocardiography only a small area of the septum and of the ventricular posterior wall can be studied; thus there remains the possibility that dyskinetic areas are missed (Kaye et al., 1975; Teichholz et al., 1976). Considering the whole of our observations we can confirm that some patients with tetralogy of Fallot have diminished or impaired left ventricular 

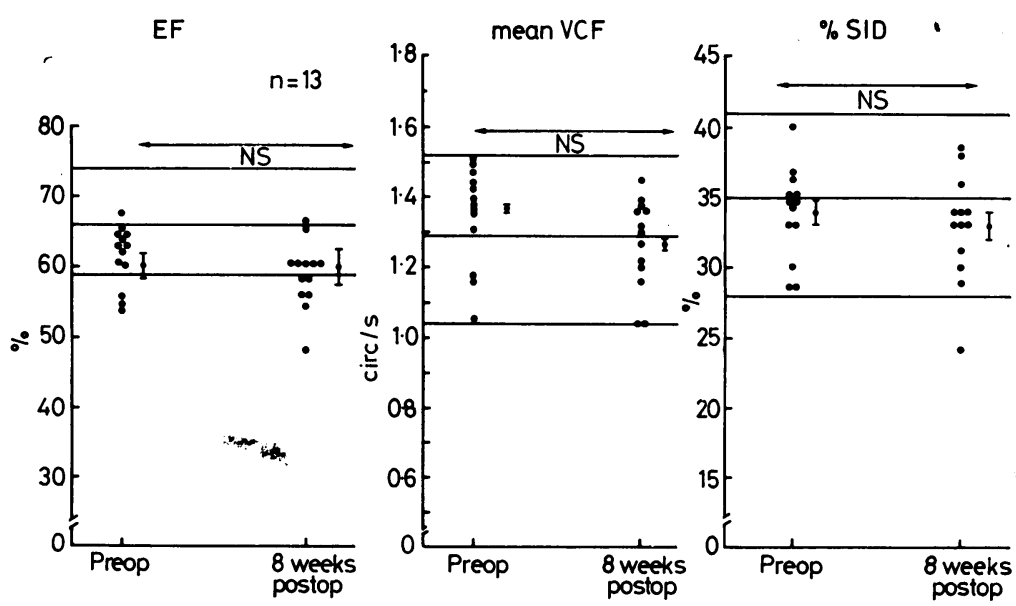

Fig. 10 Left ventricular function indices for patients with normal septal motion only $(N=13)$ before operation and 8 weeks after operation. The horizontal lines indicate the distribution of the normal values (mean \pm standard deviation). The bars show the mean values \pm the standard error of the mean. There are no significant differences between the groups for either index. EF, ejection fraction; mean VCF, mean velocity circumferential fibre shortening; $\% S I D$, per cent shortening of internal diameter.

function pre- and postoperatively. However, most children show normal function indices, whether there is abnormal septal motion or not. Certainly the abnormalities observed in our patients were less important and less frequent than those reported by Jarmakani et al. (1972).

\section{Septal movement}

Abnormal septal movement immediately after extracorporeal circulation for repair of intracardiac defects has been observed previously. The abnormal motion decreases with time after operation and in most but not all cases returns eventually to normal. The cause of this abnormal movement is still unknown but seems to be multifactorial (Righetti et al., 1977).

In tetralogy of Fallot, the interventricular septum is directly affected by the operative procedure as a Teflon patch is used for closure of the ventricular septal defect. This can cause septal injury, which in some cases may result in persistent abnormalities in septal motion. Nevertheless, after a relatively short time ( 9 weeks), 50 per cent of the operated cas returned to normal septal motion. At that time another 31 per cent still showed paradoxical and 19 per cent persistently flat motion.

In the presence of a complete bundle-branch block with left anterior hemiblock paradoxical movement is known to persist; 2 of our patients have abnormal septal motion probably related to this cause (Assad-Morell et al., 1974). Another patient had a large perioperative myocardial infarction which can be held responsible for the abnormal movement even 18 months after operation. For the 5 remaining patients with paradoxical and the 5 patients with flat motion we do not have an explanation; time will tell whether they will finally return to normal. Though an open or absent pericardium can be the cause of septal movement abnormalities, we do not believe that this is the main cause in our cases since 50 per cent of the patients have returned to normal excursion by 8 weeks after the procedure. But it could explain the early postoperative observation of increased anterior movement of the entire heart during systole from absence of restraint (Payvandi and Kerber, 1976).

Finally, one would expect right ventricular volume overload in the case of significant pulmonary $N$ insufficiency to be a cause of persistence of abnormal motion. This may have played a role in 3 of our patients, the only ones with haemodynamically significant pulmonary insufficiency. In these, septal motion remained paradoxical in 1 case and flat in 2 . It cannot be held responsible for abnormal septal motion in the other cases. Indeed the fact that right ventricular dimension decreased in nearly every case is an argument against significant volume overload in our series.

The most striking observation concerning septal movement was the fact that 31 per cent of the operated children showed normal but excessive septal motion 2 weeks after surgery. When these 
patients were evaluated by cardiac catheterisation all but one were found to have a residual pulmonary gradient of more than $30 \mathrm{mmHg}$ and in 3 cases even of above $60 \mathrm{mmHg}$. Therefore we believe that early appearance of normal but excessive septal movement should be considered indicative of a persistent pulmonary stenosis in patients who had a repair procedure for tetralogy of Fallot.

\section{References}

Assad-Morell, J. L., Tajik, A. J., and Guiliani, E. R. (1974). Echocardiographic analysis of the ventricular septum. Progress in Cardiovascular Diseases, 17, 219-237.

Chung, K. J., Nanda, N. C., Manning, J. A., and Gramiak, R. (1973). Echocardiographic findings in tetralogy of Fallot (abstract). American fournal of Cardiology, 31, 126.

Cooper, R. H., O'Rourke, R. A., Karliner, J. S., Peterson, K. L., and Leopold, G. R. (1972). Comparison of ultrasound and cineangiographic measurements of the mean rate of circumferential fiber shortening in man. Circulation, 46, 914-923.

Epstein, M. L., Goldberg, S. J., Allen, H. D., Konecke, L., and Wood, J. (1975). Great vessel, cardiac chamber, and wall growth patterns in normal children. Circulation, 51, 1124-1129.

Feigenbaum, H. L. (1972). Echocardiography. Lea and Febiger, Philadelphia.

Fortuin, N. J., Sherman, M. E., Hood, W. D., Jr., and Craige, E. (1971). Determination of left ventricular volumes by ultrasound. Circulation, 44, 575-584.

Friedli, B., Haenni, B., Moret, P., and Opie, L. H. (1977). Myocardial metabolism in cyanotic congenital heart disease studied by arteriovenous differences of lactate, phosphate and potassium at rest and during atrial pacing. Circulation, $55,647-652$.

Godman, M. J., Tham, P., and Kidd, B. S. L. (1974). Echocardiography in the evaluation of the cyanotic newborn infant. British Heart fournal, 36, 154-166.

Graham, T. P., Jr., Cordell, D., Atwood, G. F., Boucek, R. J., Jr., Boerth, R. C., Bender, H. W., Nelson, J. H., and Vaughn, W. K. (1976). Right-ventricular volume characteristics before and after palliative and reparative operation in tetralogy of Fallot. Circulation, 54, 417-423.

Graham, T. P., Jr., Jarmakani, J. M., Canent, R. V., Jr., and Morrow, M. N. (1971). Left heart volume estimation in infancy and childhood: reevaluation of methodology and normal values. Circulation, 43, 895-904.

Green, D. G., Carlisle, R., Grant, C., and Bunnell, I. L. (1967). Estimation of left-ventricular volume by one-plane cineangiography. Circulation, 35, 61-69.

Jarmakani, J. M., Graham, T. P., Jr., Canent, R. V., Jr., and Jewett, P. H. (1972). Left heart function in children with tetralogy of Fallot before and after palliative or corrective surgery. Circulation, 46, 478-490.

Karliner, J. S., Gault, J. H., Eckberg, D., Mullins, C. B., and Ross, J., Jr. (1971). Mean velocity of fiber shortening: a simplified measure of left-ventricular myocardial contractility. Circulation, 44, 323-333.

Karliner, J. S., Hirshleifer, J., Crawford, M., and O'Rourke, R. A. (1975). Effects of heart rate, afterload and chronic digoxin administration on cardiac performance in normal human subjects (abstract). Clinical Research, 23, 125A.
Karliner, J. S., and O'Rourke, R. A. (1975). Usefulness and limitations of assessment of internal shortening velocity by ultrasound in man. Chest, 68, 361-364.

Kaye, H. H., Tynan, M., and Hunter, S. (1975). Validity of echocardiographic estimates of left-ventricular size and performance in infants and children. British Heart fournal, 37, 371-375.

Kirklin, J. W., and Karp, R. B. (1970). The Tetralogy of Fallot. W. B. Saunders, Philadelphia.

Lev, M., and Eckner, F. A. O. (1964). The pathologic anatomy of tetralogy of Fallot and its variations. Diseases of the Chest, 45, 251-261.

Lev, M., Rimoldi, H. J. A., and Rowlatt, U. F. (1964). The quantitative anatomy of cyanotic tetralogy of Fallot. Circulation, 30, 531-538.

Levin, A. R., Boineau, J. P., Spach, M. S., Canent, R. V., Jr., Capp, M. P., and Anderson, D. A. W. (1966). Ventricular pressure-flow dynamics in tetralogy of Fallot. Circulation, 34, 4-13.

Meyer, R. A., Stockert, J., and Kaplan, S. (1975). Echographic determination of left ventricular volumes in pediatric patients. Circulation, 51, 297-303.

Morris, D. G., Felner, J. M., Schlant, R. C., and Franch, R. H. (1975). Echocardiographic diagnosis of tetralogy of Fallot. American fournal of Cardiology, 36, 908-913.

Paraskos, J. A., Grossman, W., Saltz, S., Dalen, J. E., and Dexter, L. (1971). A non-invasive technique for the determination of velocity of circumferential fiber shortening in man. Circulation Research, 29, 610-615.

Payvandi, M. N., and Kerber, R. E. (1976). Echocardiography in congenital and acquired absence of the pericardium. Circulation, 53, 86-92.

Pombo, J. F., Troy, B. L., and Russel, R. O., Jr. (1971). Left ventricular volumes and ejection fraction by echocardiography. Circulation, 43, 480-490.

Popp, R. L., Filly, K., Brown, O. R., and Harrison, D. C. (1975). Effect of transducer placement on echocardiographic measurement of left ventricular dimensions. American fournal of Cardiology, 35, 537-540.

Righetti, A., Crawford, M. H., O'Rourke, R. A., Schelbert, H., Daily, P. O., and Ross, J., Jr. (1977). Interventricular septal motion and left ventricular function after coronary bypass surgery. Evaluation with echocardiography and radionuclide angiography. American fournal of Cardiology, 39, 372-377.

Snedecor, G. W., and Cochran, W. G. (1970). Statistical Methods. Iowa State University Press, Ames, Iowa.

Tajik, A. J., Gau, G. T., Ritter, D. G., and Schattenberg, Th. T. (1973). Echocardiogram in tetralogy of Fallot. Chest, 64, 107-108.

Teichholz, L. E., Kreulen, Th., Herman, M. V., and Gorlin, R. (1976). Problems in echocardiographic volume determinations: echocardiographic-angiographic correlations in the presence or absence of asynergy. American fournal of Cardiology, 37, 7-11.

Tynan, M. Reid, D. S., Hunter, S., Kaye, H. H., Osme, S., Urquhart, W., and Davies, P. (1975). Ejection phase indices of left ventricular performance in infants, children and adults. British Heart fournal, 37, 196-202.

Requests for reprints to Dr I. Oberhänsli, Clinique Universitaire de Pédiatrie, 30 Boulevard de la Cluse, CH.1211, Geneva, Switzerland. 